\title{
Assessing Effective Attributes Of Followers In A Leadership Process
}

Absael Antelo, University of the Incarnate Word, USA Evgenia V. Prilipko, University of the Incarnate Word, USA

Margaret Sheridan-Pereira, Trinity College, Ireland

\begin{abstract}
Followership, being an understudied concept, raises fundamental questions: How did followership develop? Why do people submit into becoming followers? The developmental trajectory for the development of individual attributes is as yet, uncharted. Current study provides an overview of assessed attributes of followers, as proposed by Antelo (2010). Statistical survey design and correlation procedures are applied to assess selected variables and their relationship when examining the results of a multicultural survey conducted among leaders and followers in Russia, Belarus, United States, Bolivia, Mexico and Italy, totaling in over 400 members. Findings indicate that individual worker motivation influences performance and productivity. Results of the study also illustrate that leaders typically rate themselves higher than followers do. The study discusses the need to understand how individual traits are developed, discovered, and how individuals can be formed, nurtured and prepared to become effective leaders as well as effective followers. The criticality of certain attributes characteristic to both leaders and followers is examined along with the need to analyze how some attributes can be changed. Evolutionary approach in personal development and formation of individual attributes is taken into a great consideration.
\end{abstract}

Keywords: Followership, leadership process, personal attributes of followers, assessing effective attributes.

\section{INTRODUCTION}

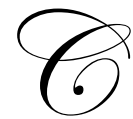

ome follow go lead, represents a new focus of the studies on followership. In effect, leadership is too important to be left to leaders alone (Grint, 2000, p.4). Followership, being an understudied discipline, raises fundamental questions of primary importance: How did followership develop? Why do people submit into becoming followers? Van Vugt (2009) examines this issue from a biological and historical point of view; he investigates the process of leader-follower relationship development and change over several stages of human evolution, "from simple band leadership to the complex, multilayered leadership arrangements of today" (p.54). Van Vugt (2009) believes that "the key to the emergence of followership, and its logical extension, leadership, lies in the need for group coordination. In species in which individuals are better off acting together, leader/follower patterns are likely to be found" (p.54).

This interactive nature helps us to understand leadership as the process used for "inducing others to coordinate their actions or goals with that of the individual, the leader, to foster the leader's proximate goals" (Van Vugt \& Kurzban, 2007, p. 4). In this context, "followership is defined as design to coordinate one's action or goals with that of another individual, the leader, in order to foster the leader's proximate goals" (Van Vugt \& Kurzban, 2007, p.4.)

Robert Kelly, a followership pioneer, presented his first articles on the subject in the late 1980s (Kelley, 1988). Smith (1996) later on declared: "Today, in an effective organization, people must both think and do, manage others and manage themselves, both make decisions and do real work... Few people who only follow will contribute to such organizations. Nor will many who only lead. Instead, all must learn how to both lead and follow." "While leaders contribute a maximum of $20 \%$ to organizational success, followers contribute an estimated $80 \%$ to the success of the organizations" (Kelley, 1992). 
All leaders should at some point experience what it is to be a follower. Aristotle once noted (Goffee and Jones, 2006) that "all great leaders must first learn to follow." Although the traditional view is that "leaders act and followers mainly react," as discussed by Avolio (2007), the opposite is true: "Leaders also are followers, and followers also exhibit leadership" (Hackman \& Wageman, 2007, p.45). Authors Townsend and Gebhardt (2003) concur with that conclusion by saying that "all employees, including leaders, exhibit followership behaviors at some time or another." Hackman and Wagemen (2007) argue that "It can take a good measure of skill and personal maturity to balance between one's simultaneous roles as leader and as follower" (p.46).

\section{STATEMENT OF THE PROBLEM}

The act of leading is a complex process people engage in to fulfill a variety of personal and professional purposes. Some individuals effectively create and communicate attractive goals or desirable scenarios whilst others are prepared to dedicate time and effort to reach them. Presumably these individuals are inherently different. The origin of their different personalities and attributes may be genetic or indeed acquired. The anatomic (biologic or physiologic) correlates of these attributes may be evident at or even before birth. Nonetheless, the impact of nurturing or adverse environmental factors during the prolonged human period of human growth and development may shape their acquisition of specific skills, distinctive tastes and cognitive capacities, and, therefore, their unique identities. The developmental trajectory for the development of individual attributes is as yet, uncharted. However, variation for the developmental time course of individual attributes is to be expected. This latter anticipated variability should prove beneficial as potential for ongoing influence will remain for some attributes. Prominently, these individuals are also people who differ genetically and whose personality and attributes are evident at birth, perhaps before, and who, by receiving the impact of environmental influences as they grow, develop an identity, specific skills, distinctive taste and different levels of intelligence. A key task is to understand the factors influencing the development of how such individual traits are developed, and to discover to what extent formative processes are susceptible to genetic and environmental factors both of a nurturing, enriching, and adversarial nature. Such understanding of individual formation may result in capacity to prepare, nurture and educate individuals for effective leadership and followership roles and responsibilities.

Leadership subjectively takes place in a social interaction process. Then, suddenly an opportunity to lead arises for those who were first members or followers in a team, group, or in an organization. This phenomenon of transformation generates further research interest among researchers to determine the beginning and end of the process. If these two milestones are established, then it will be easier to effectively teach, and, therefore, learn leadership. For instance, to quote Van Vugt, "it is not clear why individuals choose to become leaders" or are assigned leadership roles, "and it is even more puzzling why people voluntarily submit to leaders and become followers" (Van Vugt, 2006, p.355). The complexity of the process is apparent, and, as such, it stirs a debate. For some, leadership seems to be a social process by which dominance and submission takes place. On one hand, leaders are identified as the superiors and supervisors, and, on the other hand, followers as subordinated members who submit themselves to the leaders.

\section{PURPOSE OF THE STUDY}

The purpose of this study is primarily to assess the followership attributes which subordinates and team members bring to the workplace where a leadership process is taking place. Determining the most effective personal attributes of the followers facilitates an understanding of behaviors of both - leaders and followers. This paper is intended to share research-based information for the assessment and understanding of followership as it happens in a leadership process. Although, the literature is replete with leadership approaches, it remains as the most observed and least understood human action. Some studies on leadership have produced significant findings which have helped to differentiate between leader and follower personal attributes and their consequent behaviors (SEDL, 1992). However, little attention has been given to the followers' contribution to the leadership process. This research line represents a continuation of research by Antelo \& Henderson on the process model of leadership begun in 2006.These initial research efforts concentrated on leader held attributes that contribute to the leadership process, whereas the current research is focusing on the much neglected follower aspect in the leadership process. 


\section{LITERATURE REVIEW}

Follower attributes are one of the fundamental components of leadership along with the social and work environment. Although the latter two have been studied, the followers' significance in the leadership process has not been clearly established. Regardless of the fact that Hersey and Blanchard (1982) view followership characteristics as "one of the independent variables of the leadership process," current paper presents such a concept as an independent free standing unit, as a notion of "personal attributes of followers." Follower characteristics have not been given a fair amount of attention, and, according to Hur (2008), they have been "buried in the study of the leader-follower relationship" (p.367).

Numerous studies have shown various followers characteristics proposed. Nolan and Harty (2001) believe that followers' attributes are the same as leaders' attributes proposed by Giammatteo (1981): Sensitivity, selfidentification, listening ability, absence of ridicule, ability to communicate, understanding of the needs of others, recognition of everyone's worth and willingness to share responsibility.

A review of Leadership Behavior Description Questionnaire (LBDQ) by Hemphill and Coons (1950) suggests additional followership attributes: Making attitudes clear, maintaining performance standards, informing others as to what is expected of them, treating others equally, being friendly and approachable and accepting suggestions of others. Other attributes of good followership suggested by researchers are intelligence, cooperativeness, diplomacy and sociability, as introduced by Stogdill and Coons (1957) are also viewed as traits of leadership. As Nolan and Harty (2001) stated, "leadership and followership go hand in glove" and their attributes should be corresponding.

When applying attribution approaches posed by Heider (1958) to followership attributes being reviewed, one may conclude that observers tend to disregard situational factors and overstress the internal attributes of followers when making causal attributions. Moreover, leadership perceptions of followers may be dramatically influenced by the fundamental attribution error. According to Heider (1958), "observers attribute characteristics to actors on the basis of the actor's behavior" (Schyns \& Hansbrough, 2008). Thus, in a followership context, leaders attribute characteristics to their followers based on the followers' behavior. The following attribution process differentiates between internal attributions to the individual and external attributions to the situation (Schyns \& Hansbrough, 2008). The attribution of mistakes has a high significance for organizations. In order to prevent the occurrence of costly mistakes, leaders are to evaluate mistakes and establish their grounds.

\section{PERSONAL ATTRIBUTES OF FOLLOWERS}

An attempt to derive a synopsis of the most significant attributes resulted in a list well supported by the literature. Current paper introduces a new perspective on personal attributes of followers, as proposed by Antelo (2010). "Attribute," by definition, is "something attributed as belonging to a person, thing, group, etc.; a quality, character, characteristic or property" (Attribute, 2010). The notion of an attribute can be enhanced by the concept of an attribution theory, developed by Kelley (1992). Attribution theory aims to explain the ways individuals judge others, based on the meaning they attribute to a specific behavior. Personal attributes of followers being examined are discussed as follows.

\section{Facility for interpersonal relations}

Followers are expected to demonstrate an ability to connect with others easily in an adequate period of time. They strive towards cultivating a nurturing interpersonal work climate with other team members. Respectful, harmonious relationships with coworkers are a manifestation of a social commitment leading to one's feelings of acceptance in the work place, contention and self-efficacy.

The notion that interpersonal skills can be learned and developed offers one the possibility to become a more effective follower. In a study conducted to assess the relationship among relational exchange quality, perceived organizational support (POS), and organizational identification was found that subordinate POS mediates the relationship between leader-member exchange and organizational identification. In addition, it is suggested that 
"higher quality of the relational context produces a spillover of resources and reduces the negative association between lower quality leader-member exchange and POS." Researchers suggested they have "expanded the purview of social exchange theory by including other proximal (and interpersonal) relationships as context for social exchange between the individual and organization" (Sluss, Klimchak, and Holmes, 2008).

Additional contextual trend is taking place, older workers reporting to a much younger supervisor. This is being identified as a relational demography. A major change from tradition is that older workers expect less from their younger supervisors than do younger workers. As a result, older workers rate their younger supervisors' leadership behavior lower than younger workers rate their younger supervisors (Collins, Hair, and Rocco, 2009).

\section{Facility for group relations and functions}

Followers are expected to experience and demonstrate an adequate level of comfort when working in a team. Followers work effectively as a team in order to achieve organizational goals, support each other and their leader (Solovy, 2005). In fact, "team members have been shown to have such a powerful effect on fellow group members that their help and support ameliorate the negative effects of unmet expectations" (Major, Kozlowski, Chao, \& Gardner, 1995). Team performance and leadership are organizational processes affected by the quality of the working relationship established between leaders and followers. Clearly, leadership involves "mutual goalenactment behavior and working relationship both between individual followers and between follower and leader" (Graen, 2009, p.52).

\section{Tolerance}

In a general meaning "tolerance is the ability to accept something while disapproving of it" (Tolerance, 2010). Followers are advised to exhibit a reasonable amount of tolerance when working individually or as a team. In practice, tolerance indicates followers' support of practices, actions or decisions carried out by management and coworkers in spite of their intrinsic disagreement with such actions. Power seems to be linked to elements of intensity of tolerance. In a study about the use of power in the supervisory relationship from supervisees' perspectives it was suggested that "supervisors' power practices included discussions of power, empowering supervisees, promoting an atmosphere of safety, collaboration with supervisees, imposition of style/orientation, and misuses of power, such as violation of confidentiality" (Murphy and Wright, 2005). The practices used by the supervisees included, supervisee-peer power, supervisees as consumers, and withholding information (Murphy and Wright, 2005).

Elements of distributed leadership seem to be connected to followers' tolerance to control and compliance. The claim is that if the intention is to build organizations that are more democratic and respectful of the human status or their members and other stakeholders, then distributed leadership may provide an opportunity to advance its democratic potential (Woods and Gronn, 2009).

\section{Conceptual understanding}

Followers are expected to possess necessary job-related background and be equipped with required skills and abilities appropriate to the job. Followers are to have a thorough understanding of project-related processes, the reasons, goals and consequences of the given task. Followers are to develop and engage their own independent critical thinking and strive for continuous learning.

Long term observations of organizational problems have proved that formulation and fulfillment of a psychological contract on the part of leaders and followers seems to be an effective process to create a fulfilling, stimulating, and freedom-to-think, creative work environment. With increased clarity of understanding of the work environment and supportive leadership, employees will go beyond the job minimums and offer creative, 'out-of-thebox' contributions (Cangemi, and Miller, 2007).

Being able to do a task well requires on the part of the followers, an understanding of the information related to the job. In this light, leaders as well as followers can use different strategies to acquire the required 
knowledge. "Empowerment seems to describe many of the dynamics inherent in the relationship that links effective, independent-thinking followers with effective leaders" (Lee, 1991). In essence, effective followers are those individuals who are able to perform conceptual transfer to solve task-related problems. According to Lee (1991), these effective subordinates have been characterized as having: (1) personal integrity that demands loyalty to the organization and willingness to act in their own beliefs, (2) an understanding of the organization and their contributions to it, (3) versatility, and (4) responsibility (Lee, 1991).

In an attempt to assess the association between followers' personality and leadership, subordinates rated their immediate superior on transformational, transaction, and passive-avoidant leadership measured by the Multifactor Leadership Questionnaire and completed the NEO-FFI, with the five traits - neuroticism, extraversion, openness, agreeableness, and conscientiousness. Results indicated that followers' personality was only moderately associated with leadership ratings. However, other links were revealed between transformational leadership and followers' level of neuroticism and agreeableness; and between ratings of passive-avoidant leadership and subordinates' level of agreeableness and openness (Hetland, Sandal, and Johnsen, 2008).

External forces to the established business corporations are also significant challenges for effective leaders and also for followers. The success of the leaders depends on their ability to develop a base of loyal, capable, and knowledgeable followers (Lundin, and Lancaster, 1990). However, effective followership is vital at every level of the organization. The misconception that leaders do all the thinking and that followers simply carry out orders should be buried while followership must be nurtured. Characteristics that make followers effective include integrity, owning the territory, versatility, and self-employment. Followership can be nurtured by re-conceptualizing the workplace, institutionalizing followership, hiring and training for followership, and recognizing and celebrating followership (Lundin and Lancaster, 1990; Riggio, Chaleff, and Lipman-Blumen, 2008).

Having an imposing title does not make one a leader. True leaders inspire commitment from executives, managers, staff, and clients. "What separates a true leader from a titled executive? Leaders have followers" (Atchison, 2003). The author also suggests that a leader should act with proven strategies that increase morale and result in employees who are truly committed.

\section{Facility for learning and embracing change}

Being able to easily adapt to ever-changing circumstances in the workplace is an essential trait of followers. Ability to let go of the past experiences, attitudes and thoughts and become open to change is a remarkable quality of followers. Good followers should be able to "analyze the information given to them, meticulously evaluate situations and actions, and make judgments independent of the political consequences of decisions" (Kelley, 1992; Latour \& Rast, 2004). These followers are innovative, creative and eagerly open to new ideas.

Achieving extraordinary organizational performance requires among other things, non-traditional managers, who can develop management responsibility in subordinates and develop the subordinates' abilities to the point where they can share management of the unit's performance. Bradford, and his associates called this approach, manager-as-developer, a "postheroic" leader. Under this perspective, (1) tasks are likely to be completed with a higher level of quality, (2) subordinates feel responsible for the successful management of the unit, and (3) subordinate motivation is increased (Bradford and Cohen, 1984).

Change cannot be done without the engagement of the followers. Defining followers as subordinates who have less power, authority and influence than their superiors, and who usually, but not always, fall into line, Kellerman notes that all individuals are followers at different points in time. She identifies five types of followers based upon their level of engagement: Isolate, Bystander, Participant, Activist and Diehard. She explores each type, with examples ranging from Nazi Germany to Merck to the U.S. military's Operation Anaconda in Afghanistan. Followership is not about changing the rank of followers, Kellerman states, but instead about changing their response to their rank, their superiors and the situation at hand (Kellerman, 2008).

Unconventional leaders are also likely to produce an impact on follower motivation to embrace change. Jaussi and Dionne (2004)conducted a study to examine the relationship between a leader's unconventional behavior 
and followers' satisfaction, perception of leader effectiveness, and perception of effort exerted in an experimental setting. Their "results indicated that above and beyond leadership style (i.e., transformational and transactional), unconventional behavior (e.g., standing on furniture, hanging ideas on clotheslines) is significantly related to follower satisfaction with the overall experience and perceptions of leader effectiveness" (Jaussi and Dionne, 2004).

\section{Facility for effective communication}

Being able to communicate effectively with both supervisors and team members is crucial for followers. Ability to deliver both positive and negative news in the most appropriate way is not an easy task and requires experiences, courage, and skills. Followers should be able to communicate new perspectives with respect regardless of whether their ideas are accepted or not.

\section{Reliability as a group member}

When team members consider one to be a reliable group member, it is an important quality for a follower and is one of the cornerstones of one's reputation in the workplace. Good followers "trust and work effectively with others, embrace change, perform their job competently, identify with the leader, and share the leader's vision" (Latour \& Rast, 2004). In a study conducted to assess whether or not training intervention would help managers adopt a more autonomy-supportive motivating style toward employees and whether or not the employees of these managers would, in turn, show greater autonomous motivation and workplace engagement. Results indicated that some employees "showed significantly more autonomous motivation and greater workplace engagement than did employees supervised by control-group managers" (Hardre and Johnmarshall, 2009).

\section{Facility for contribution to the group}

Being able to act as a cohesive member of the group and being able to fairly contribute to the overall assignment of the group makes a follower a respected and a welcomed member of the group. Exemplary followers work beyond of what is asked of them.

\section{Emotional intelligence}

By definition, emotional intelligence is "a capacity, ability, skill, or self-perceived grand ability to identify, assess, and manage the emotions of one's self, of others, and of groups" (Emotional Intelligence, 2010). According to Robbins and Judge (2009), emotional intelligence is one's ability to be "self-aware..., detect emotions in others, and manage emotional cues and information" (p.264). Followers with a high level of emotional intelligence are capable of being the most effective by controlling their own behavior and expressing themselves in a graceful manner.

In a study aimed at testing the relationships subordinates and supervisor trait emotional intelligence levels and their perception of the supervisory working alliance, Cooper \& $\mathrm{Ng}$ (2009), found that supervisees and supervisors with higher levels of trait EI tended to perceive the supervisory working alliance more positively.

\section{Facility for supporting others}

Being able to provide emotional support to colleagues, customers and other people involved in the work process is an invaluable attribute of followers. However, not all individuals are capable of providing comfort, care and support to their colleagues due to their unique personalities. Facility for supporting others does not only imply the ability to provide support of emotional needs, but also the capacity to support the innovative ideas and creativity of other coworkers.

This attribute seems to be associated with the ability of the follower to overcome problematic situations. A study evaluated the relationship between leader behaviors and subordinate resilience. It was proposed that the transformational leadership dimensions of Attributed Charisma, Idealized Influence, Inspirational Motivation, Intellectual Stimulation, and Individualized Consideration, as well as the transactional leadership dimension of 
Contingent Reward would be positively associated with subordinate resilience. These hypotheses were all supported. In addition, it was found that participants who mentioned their leaders as a positive factor in dealing with the situation exhibited greater resilience than participants who did not (Harland, Harrison, Jones, and Reiter-Palmon, 2004).

Similarly, in an effort to assess trust from a followers' perspective, it was found that there is a positive relationship between felt trustworthiness by the subordinates and measures of their performance, organizational citizenship behavior, and job satisfaction (Lester and Brower, 2003). Supporting others involves social aspects of behavior. A study was conducted to test whether or not pride and gratitude were associated with the pro-social behaviors - social justice and altruism, exhibited by organizational leaders. Results revealed that a leader's propensity to experience authentic pride was positively related to these two measures: Social justice and altruism (Michie, 2009).

\section{Flexibility}

Followers are expected to adapt to changing circumstances at the workplace and be able to quickly reanalyze and adjust their behavior according to the situation at hand. Situations requiring a swift new approach to the existing problem may vary from having to adapt to the new software program to having to arrange medical help for an injured coworker. Good followers are capable of developing cognitive flexibility, which allows them to effortlessly shift from one task to another, multitask, manage assignments well, and prioritize accordingly. When exhibiting emotional flexibility, followers are able to express their full range of emotions appropriate to the situation at hand.

Interpersonal perceptions of trustworthiness in a work situation can influence levels of flexibility and the way followers see their leaders. It has been established that leadership behaviors influence trustworthiness. In a study conducted by Caldwell and Hayes (2007) it was found that three dimensions of leadership behavior: Relationship development, resource utilization, and image management were related to three dimensions of trustworthiness: Ability, benevolence, and integrity. More specifically, it was reported that image management influences the three dimensions of trustworthiness; whereas relationship development influences the benevolence dimension of trustworthiness (Caldwell and Hayes, 2007).

\section{Motivation for goal accomplishment}

Being self-motivated from within is a highly desirable quality in followers. Leaders appreciate selfmotivation in followers as opposed to artificial motivation guided by financial rewards, perks, or other quasistimulators as driving sources. Followers are courageous and honest individuals who "formulate their own meaning of life rather than pursue societal goals such as money, status, and fame. They do not compete for leadership or power. Instead, they cooperate to accomplish goals" (Kelley, 1992).

Performance and innovation are important factors to any competitive organization. Clearly, it is generally expected that leadership influences followers' effective performance. In a study precisely designed to assess these variables, researcher reported that transformational leaders boost subordinate performance by stimulating organizational citizenship behavior when they enhance follower innovation by triggering controversial discussion of task related issues (Boerner, Eisenbeiss and Griesser, 2007).

Another promising element to be considered for motivating followers toward goal accomplishment is the regulatory focus theory. Under this promotion focus, transformational leadership inspires only followers who direct their attention to their aspirations. In addition, followers focus their attention on aspirations only when they experience a sense of security. According to this study conducted by Moss (2009), 160 employees evaluated the leadership style of their supervisors and their own regulatory focus, self-esteem, attachment style, belief in a just world, and work engagement. Results indicated that visionary leadership was positively associated with engagement in followers, especially when those individuals adopted a promotion focus (Moss, 2009). 


\section{RESEARCH DESIGN}

The basic quantitative inquiry system for this study is the Statistical Survey Design. In addition, correlational procedures are also applied to assess selected variables and their relationships. Some demographic data such as gender, age, education, and experience were collected. The survey instruments include items and questions related to personal attributes. Descriptive and inferential statistics are used for the data analysis in an attempt to provide answers to the research problem.

\section{SETTING}

The study is a component part of an ongoing line of research on the process of leadership and it was conducted in natural organizational settings where leaders and followers are involved in a real work situation. The research sample included managers, supervisors, and members of work teams from Russia, Belarus, the United States, Bolivia, Mexico, and Italy.

\section{SAMPLE}

The total sample amounts to 400 members. This subgroup is composed of leaders and followers who are currently working as managers, supervisors and subordinates. These individuals belong to business, educational, health care organizations, and other service institutions.

\section{DATA COLLECTION}

Data were collected online through surveymonkey.com during 2009 and the spring 2010. A survey instrumentation composed of three sections was used for data collection. The FSAI-1, Follower Self Assessment Inventory - short form, the LFAI, Leader Follower Assessment Inventory, and the FSAI-2 Follower Self Assessment Inventory. These questionnaires are considered reliable, Crombach's Alpha .85 (Henderson, 2007).

\section{PRELIMINARY FINDINGS}

According to the literature review conducted, research in work group motivation indicates that individual worker motivation influences performance and productivity. A paramount task for the leader is to determine the factors that impact work motivation as well as the motives leading to extraordinary performance. Employees, however, respond in a variety of ways to their jobs and their organizations' practices. The assumption is based on the premise that individual attributes are brought to the workplace by each member of the group. In addition, the concept of individual differences involves personal needs, values, attitudes, interests and abilities individuals bring to their workplace. Job characteristics refer to the nature of the position and thus determine its limitations and challenges. Organizational practices are the rules, policies, managerial practices, and reward systems. This complexity is increased with the construct of motivation which is understood as the process that moves one toward a goal. As a consequence, employees possess a full control of their own behaviors. The leader, in turn, attempts to influence the factors that motivate employees.

Preliminary findings of the study indicate that typically leaders rate themselves higher than followers do. This perception shows followers having critical differences, especially in variables related to communication, interpersonal relations, and flexibility. Final results will be presented at the conference.

According to the initial data analysis, participants included $26.88 \%$ males and $73.12 \%$ females. The majority of the members of the sample are from Russia (62.26\%), Belarus (30.19\%) and other countries (7.55\%). 
Table 1. Mean values of the followers' attributes

\begin{tabular}{|l|c|c|c|}
\hline \multicolumn{1}{|c|}{ Attribute } & Mean & Std. Error & Std. Deviation \\
\hline Reliability as a group member & 3.74 & .089 & .919 \\
Supporting others & 3.47 & .093 & .958 \\
Contribution to the group & 3.39 & .079 & .811 \\
Conceptual understanding & 3.32 & .087 & .900 \\
Emotional intelligence & 3.20 & .095 & .980 \\
Group relations & 3.20 & .081 & .833 \\
Effective communication & 3.16 & .086 & .885 \\
Flexibility & 3.14 & .099 & .018 \\
Motivation for goal accomplishment & 3.13 & .089 & .916 \\
Interpersonal relations & 3.06 & .079 & .815 \\
Tolerance & 3.02 & .107 & .093 \\
Learning and embracing change & 2.90 & & .104 \\
\hline
\end{tabular}

Note: $\mathrm{N}=106$ research participants.

As it is depicted in Table 1, participants seem to indicate that the majority of the attributes are considered not only important for an effective leadership process but also that they are in possession of these attributes. Furthermore, they bring these attributes to the workplace and situations in which a leadership process takes place. However, the capability to learn and embrace change was the lowest rated attribute, whereas reliability as a group member was the highest rated attribute.

The results presented in Table 2 indicate that there is no significant difference between female and male ratings of all attributes. It is interesting to highlight the fact that both females and males rated their reliability as a group member as the highest attribute. Females rated learning and embracing change as the lowest attribute, and males rated interpersonal relations, and learning and embracing change, as the lowest attributes. Additionally, a Pearson Moment Correlation procedures were performed to these subgroups and results indicated that females' and males' ratings are correlated $(r=77)$. Finally, the researcher performed statistical procedures to determine the reliability of the instruments used. Results proved the instruments to be highly reliable having a Cronbach's Alpha coefficient of .990 .

Table 2. Mean values by gender

\begin{tabular}{|l|cc|cc|}
\hline \multicolumn{1}{|c|}{ Followers' Attributes } & \multicolumn{2}{c|}{ Female } & \multicolumn{2}{c|}{ Male } \\
Mean & \multicolumn{2}{c|}{ Std. Dev. } \\
\hline Interpersonal relations & Mean & Std. Dev. & 3 & $(0.89)$ \\
Group relations & 3.08 & $(0.77)$ & 3.13 & $(0.88)$ \\
Tolerance & 3.22 & $(0.80)$ & 3.07 & $(1.00)$ \\
Conceptual understanding & 3 & $(1.14)$ & 3.47 & $(0.96)$ \\
Learning and embracing change. & 3.26 & $(0.86)$ & 3 & $(0.86)$ \\
Effective communication & 2.86 & $(0.98)$ & 3.17 & $(0.82)$ \\
Reliability as a group member. & 3.16 & $(0.90)$ & 3.57 & $(0.96)$ \\
Contribution to the group & 3.80 & $(0.90)$ & 3.40 & $(0.88)$ \\
Emotional intelligence & 3.43 & $(0.75)$ & 3.30 & $(0.86)$ \\
Supporting others & 3.16 & $(1.01)$ & 3.23 & $(0.88)$ \\
Flexibility & 3.57 & $(0.96)$ & 3.23 & $(0.92)$ \\
Motivation for goal accomplishment & 3.11 & $(1.05)$ & 3.20 & $(0.91)$ \\
\hline
\end{tabular}

\section{CONCLUSIONS}

At this early stage of the data analysis, it appears that leaders and followers disagree on perceptions of some personal attributes of the followers. This indicates that there are critical items leaders should address to improve their leading practices. Similarly, followers should engage in improving their awareness of those attributes they activate when performing their regular tasks at work. 
As it was mentioned earlier, participants have identified effective personal attributes considered critical for the leadership process. Some of them are reliability as a group member, supporting others, contribution to the group, and conceptual understanding. It can be argued that when such characteristics are demonstrated in practice, groups of followers may become more proficient. It was also revealed that the capability to learn and embrace change obtained the lowest rating. This may be an indicator of the complexity of the process for implementing change. In addition, reliability as a group member was the highest rated attribute. Overall findings suggest that personal characteristics are regarded to be essential in the followership process.

The results of the study reveal no significant difference between female and male ratings of all attributes. It must be recognized that both females and males rated their reliability as a group member as the highest attribute. Learning and embracing change turned out to be the lowest-rated attribute among females. As for males, interpersonal relations, and learning and embracing change were among the lowest-rated attributes.

It is possible for the followers to encounter great difficulty at modifying or changing critical attributes. Clearly, there is a need to analyze how these attributes can be changed. However, evolutionary variables and personal development must be taken into consideration to see what attributes are likely to be subject to adjustment or what attributes have an inherent plasticity by both, leaders and followers.

Van Vugt, Hogan, \& Kaiser (2008) state that "the psychology of followership is more complicated and interesting than that of leadership." Since more people are followers, there is much more research to be done, in their opinions. Wiles (1967) considers leadership and followership to be equally important. He claims that very little attention has been given to the latter one even though leadership is nonexistent without followership.

From an evolutionary point of view, it is not surprising why individuals choose to become leaders. It is more intriguing why people voluntarily submit to leaders and become followers. There is a supposition that followership has been selected for its contribution to the overall success of a group. As Van Vugt (2006) states, "Questions about the origins of followership are not normally posed in the psychological literature, but they are critical in an evolutionary analysis" (p.355).

One does not have to be in a leadership position in order to provide leadership. Hackman and Wageman (2007) suggest that among the most inspiring varieties of leadership is the one that is provided by followers, "especially followers who are unlikely ever to be selected for formal leadership positions" (p.46).

\section{AUTHRO INFORMATION}

Evgenia Prilipko is a Ph.D. student with the concentration in Organizational Leadership at the University of the Incarnate Word, San Antonio, Texas. Her three Master's degrees are in the following areas: Teaching English and French, Global Economy and International Relations, and Organizational Communication and Development. Her research interests include leadership, assessment and development of leader attributes as well as followership, assessment and development of follower attributes. Evgenia Prilipko can be contacted at prilipko@student.uiwtx.edu Absael Antelo is an Associate Professor of the University of the Incarnate Word.

Dr. Antelo has worked as President of the Bolivian Private University and of the Franz Tamayo University. He also served as a School Superintendent for the Educational Corporation Eagles' School. Dr. Antelo worked as a Vice President for Academic Affairs and Director of Graduate Studies at North Eastern University. His research is focused on leadership, intercultural learning, followership, and school administration.

Dr. Margaret Sheridan-Pereira is a neonatologist/pediatrician consultant at Coombe Women and Infants University Hospital and Our Lady's Hospital for Children at Crumlin. She also serves as a clinical senior lecturer at the Department of Peadiatrics of Trinity College in Dublin, Ireland. 


\section{REFERENCES}

1. Atchison, T. (2003). Followership: A practical guide to aligning leaders and followers. New York, NY: Health Administration Press.

2. $\quad$ Antelo, A. (2010). Lecture on "Assessing effective attributes of followers in a leadership process." Concepts of Leadership, University of the Incarnate Word, San Antonio, TX.

3. Attribute,(2010). Retrieved from www.dictionary.reference.com/browse/attribute

4. Avolio, B.J. (2007). Promoting more integrative strategies for leadership theory building. American Psychologist, 62, 25-33.

5. Boerner, S., E, \& Griesser, D. (2007). Follower behavior and organizational performance: The Impact of transformational leaders. Journal of Leadership \& Organizational Studies, 13(3), 15-26.

6. Bradford, D. L., \& Cohen, A. R. (1984). The Postheroic Leader. Training and Development Journal, 38(1), 40.

7. Caldwell, C. \& Hayes, L.A. (2007). Leadership, trustworthiness, and the mediating lens. The Journal of Management Development, 26(3), 261-281.

8. Collins, M., Hair, J., \& Rocco, T.. (2009). The older-worker-younger-supervisor dyad: A test of the Reverse Pygmalion effect. Human Resource Development Quarterly, 20(1), 21.

9. Cangemi, J. \& Miller, R. (2007). Breaking-out-of-the-box in organizations :Structuring a positive climate for the development of creativity in the workplace. The Journal of Management Development, 26(5), 401410 .

10. Cooper, J. \& Ng, K.M. (2009). Trait emotional intelligence and perceived supervisory working alliance of counseling trainees and their supervisors in agency settings. International Journal for the Advancement of Counselling, 31 (3), 145-157.

11. de Jong, R.D. (2009). Review of the book "The art of followership: How great followers create great leaders and organizations" by Riggio, A.E., Chaleff, I., \& Lipman-Blumen, J. San-Francisco, CA: JosseyBass.

12. Emotional Intelligence, 2010. Retrieved from http://en.wikipedia.org/wiki/Emotional intelligence

13. Giammattelo, M. \& Giammattelo, D. (1981). Forces on Leadership. Reston, VR: National Association of Secondary School Principals.

14. Goffee, R., \& Jones, G. (2006). The art of followership. European Business Forum, 25, 22-26.

15. Graen, G.B. (2009). Excellence in socio-technical teamwork requires both cognitive and emotional boding. American Psychologist, 64 (1), 52-53.

16. Grint, K. (2000). The arts of leadership. Oxford: Oxford University Press.

17. Hackman, J.R., \& Wageman, R. (2007). Asking the right questions about leadership. American Psychologist, 62(1), 43-47.

18. Hardre, P. \& Johnmarshall, R. (2009). Training corporate managers to adopt a more autonomy-supportive motivating style toward employees: An intervention study. International Journal of Training and Development, 13 (3), 165-184.

19. Harland, L., Harrison, W., Jones, J.R., \& Reiter-Palmon, R. (2004). Leadership Behaviors and Subordinate Resilience. Journal of Leadership \& Organizational Studies, 11(2), 2-14.

20. Heider, F. (1958). The psychology of interpersonal relations. New York: Wiley.

21. Hetland, H., Sandal, G., \& Johnsen, T.. (2008). Followers' Personality and Leadership. Journal of Leadership \& Organizational Studies, 14(4), 322.

22. Hur, M.H. (2008). Exploring differences in leadership styles: A study of manager tasks, follower characteristics, and task environments in Korean human service organizations. Social behavior and personality, 36(3), 359-372.

23. Jaussi, K.S. \& Dionne, S.D. (2004). Unconventional Leader Behavior, Subordinate Satisfaction, Effort and Perception of Leader Effectiveness. Journal of Leadership \& Organizational Studies, 10(3), 15-26.

24. Kellerman, B. (2008). Followership: How followers are creating change and changing leaders. Boston, MA: Harvard Business School Press

25. Kelley, R.E. (1988). In praise of followers. Harward Business Review, 66, 142-148.

26. Kelley, R.E. (1992). The power of followership: How to create leaders people want to follow, and followers who lead themselves. New York: Doubleday.

27. Latour, S.M., \& Rast, V.J. (2004). Dynamic followership. Air \& Space Power Journal, 18(4), 1-7. 
28. Lee, C. (1991). Followership: The Essence of Leadership. Training, 28(1), 27.

29. Lester, S.W. \& Brower, H.H. (2003). In the Eyes of the Beholder: The Relationship Between Subordinates' Felt Trustworthiness and their Work Attitudes and Behaviors. Journal of Leadership \& Organizational Studies, 10(2), 17-33.

30. Lundin, S. C., \& Lancaster, L. C. (1990). Beyond Leadership...The Importance Of Followership. The Futurist, 24(3), 18.

31. Major, D.A., Kozlowski, S.W., Chao, G.T., \& Gardner, P.D. (1995). A longitudinal investigation of newcomer expectations, early socialization outcomes, and the moderating effects of role development factors. Journal of Applied Psychology, 80, 418-431.

32. Michie, S.. (2009). Pride and Gratitude: How Positive Emotions Influence the Prosocial Behaviors of Organizational Leaders. Journal of Leadership \& Organizational Studies, 15(4), 393.

33. Moss, S.. (2009). Cultivating the Regulatory Focus of Followers to Amplify Their Sensitivity to Transformational Leadership. Journal of Leadership \& Organizational Studies, 15(3), 241.

34. Murphy, M.J. \& Wright, D.W. (2005). Supervisees' perspectives of power use in supervision. Journal of Marital and Family Therapy, 31, (3), 283-295.

35. Nolan, J.S., \& Harty, H.F. (2001). Followership - leadership. Education, 104(3), 112-113.

36. Riggio, R.E., Chaleff, I., \& Lipman-Blumen, J. (2008). The art of followership: How great followers create great leaders and organizations. San Francisco, CA: Jossey-Bass.

37. Robbins, S.P., \& Judge, T.A. (2009). Organizational Behavior. Upper Saddle River, NJ: Prentice-Hall.

38. Schyns, B., \& Hansbrough, T. (2008). Why the brewery ran out of beer: The attribution of mistakes in a leadership context. Social Psychology, 39(3), 197-203.

39. Sluss, D. M., Klimchak, M., \& Holmes, J.J. (2008). Perceived organizational support as a mediator between relational exchange and organizational identification, Journal of Vocational Behavior, 73 (3), 457 464.

40. Smith, R. (1997). Defining leadership through followership. Annual Meeting of the National Communication Association. Chicago, IL.

41. Solovy, A. (2005). Followership. Hospitals and Health Networks. www.hhnmag.com

42. Stodgill, R., \& Coons, A.E. (1957). Leader behavior: Its description and measurement. Research Monograph, 88. Columbus, Ohio State University.

43. Tolerance,(2010). In Wikipedia The Free Encyclopedia. Retrieved from http://en.wikipedia.org/wiki/Toleration

44. Townsend, P.L., \& Gebhardt, J.E. (2003). The leadership-teamship-followership continuum. Leader to Leader, 29, 18-21.

45. Van Vugt, M. (2006). Evolutionary origins of leadership and followership. Personality and Social Psychology Review, 10(4), 354-371.

46. Van Vugt, M. (2009). Despotism, democracy, and the evolutionary dynamics of leadership and followership. American Psychologist, 54-56.

47. Van Vugt, M., Hogan, R. \& Kaiser, R.B. (2008). Leadership, followership, and evolution. Some lessons from the past. American Psychologist, 63(3), 182-196.

48. Wiles, K. (1967). Supervision for better schools. Englewood Cliffs, NJ: Prentice-Hall.

49. Woods, P. \& Gronn, P. (2009). Nurturing democracy: The contribution of distributed leadership to a democratic organizational landscape. Educational Management Administration \& Leadership, 37(4), 430. 